\title{
LAS SERVIDUMBRES PREDIALES \\ EN EL DERECHO FORAL VALENCIANO MEDIEVAL
}

\author{
Manuel Vicent Febrer Romaguera \\ Universidad de Valencia
}

\begin{abstract}
SUMARIO
1. Introducción.- 2. Modalidades de servidumbres y los modos de su adquisición.- 3. Servidumbres prediales tipificadas en los fueros valencianos: 3.1. "Servitut de conservar les carreres públiques".- 3.2. "Servitut de passar".- 3.3. "Servitut de menar aygua a regar".- 3.4. "Servitut de pendre o de poar aygua en lo pou o font de son vehi".- 3.5. "Servitut d'albeurador".- 3.6. "Servitut de l'arbre d'alcú que penjarà sobre camp d'altre".3.7. "Servitut d'era". - 4. Defensa y reivindicación de las servidumbres.
\end{abstract}

\section{INTRODUCCIÓN}

El concepto de propiedad unitaria vigente en derecho romano, e incluso en el histórico hispano, determinaba una concepción de las servidumbres prediales rústicas distinta de la introducida en el derecho foral valenciano, fruto de la evolución del romano concepto de propiedad unitaria hacia una idea más solidaria del derecho de propiedad, que se había experimentado durante la Edad Media.

De este modo, el sistema de constitución de las servidumbres en derecho foral ya no se haría sollo sobre tierras de dominio pleno del fundo dominante, sino mediante un ius in re alieria, fruto de una nueva concepcion del dominio, que permitía su división y la constitución de derechos reales

"Anuario de Enoudion Medionales", 25 (1995) 
sobre el mismo, tales como las servidumbres prediales'.

Sin embargo, los romanistas fueros valencianos determinaban como principio general la presunta libertad natural de todos los bienes, tanto rústicos como urbanos, al disponer que ningún tercero podría alegar derecho a pasar, ni a hacer otra cosa por campo ajeno, si no tenía previamente constituldo el derecho de servidumbre:

"Negú no pot ni deu passar ne fer neguna cosa per altruy camp en què no ha servitut de passar ne de fer alcuna cosa..."

De este modo, se presumia la libertad de todas las tierras respecto de cualquier clase de servidumbres, debiéndose probar en todo caso la existencia de estas limitaciones sobre el derecho de propiedad de las tierras ${ }^{3}$.

En este sentido, ya el comentarista foral valenciano del siglo XIII, Albert d'Alabanya, habra dicho en sus comentarios a los fueros, que todo predio urbano o rústico se presumfa libre (quodlibet predium urbanum seu rusticum presumitur liberum), añadiendo respecto de las fincas rústicas y

\footnotetext{
'Sobre la maturaleas de las servidumbres prediales en derocho romano y en el antiguo derocho himpeso han inendo: L. BONET CORREA y J. CALDERON, Sobre la supuesta constitución idcila de las senvidumbres en las fuenses romanas, "Anuario de Historia del Derocho Espeñol" ("AHDE", 19 (1948-1949), pp. 304-346. "Pel mismo también: La constitución ud́cita de las servidumbres en el derecho comin, "AHDE", 37 (1967), pp. 531 y ๓. También S. SOLAZJ, Requisiti e modi di costituzioni delle servitú prediali Nápoles, Jovene, 1949. L. CAPOGROSSI COLOGNESI, Ricerche sulla struttura delle servitu d'aqua in diritto romaro, Milán, Giuffrt, 1966. Del mismo también La struttura della proprield e la formazione dei "iura praedionum" nell'eld repubblicana, I-II, Milán, Universita di Roma, 1969-1976. G. FRANCIOSI, Studi sulle servitú prediale, Nápoles. Jovene, 1967. B. BIONDI, Le servitú prediali nel diritzo romano (corso di lezioni), Milán, Giuffrè, 1969. J. GARCLA SÁNCHEZ, El origen de las senidumbres prediales y su vinculación con las relaciones de vecindad en el derecho romano, "AHDE", 85-86 (julio-diciembre, 1974), pp. 35-70.-Sobre las servidumbres en el derocho hiatórico español anterior a la Recepción del derecho común, ha tratado recientemente: Francieco L. PACHECO CABALURO, Las senvidumbres prediales en el derecho histórico espantol. Lleide, Pagts Editores, 1991.

${ }^{2}$ Furs e ordinacions fetes per los gloriosos reys d'Aragó als regnicols del Regne de Valincia (en adelente, Furs e Ondinacions). Edición faceímil de 1977. Lib. III. Rub. XVI. Fur IV. Este fuero reproducía literalmente la Ley C. 11: De eervitutibus et aqua, 3, 34. También se hallaba en las Costums de Tortosa (Lib. III, Rub. De servituts d'aygues, de parts e de altres coses. Cot. V, purrafo 1.

'Loe fueroo valencianoo dejaban bien claro que a nadie se le podía impedir hacer aquello que quisiers en aus biens mientras no fuera en contra de las leyes: "...cascú pol fer e'l seu ço que ell volrh, eol que no sia vedat en dret ço que ell hi fard" (Cfr. Furs e Ordinacions, Lib. III, Rub XVI, Fur XII).
} 
urbanas que, para considerar la existencia de una servidumbre, debra probarse.

\section{MODALIDADES DE SERVIDUMBRES $Y$ LOS MODOS DE SU ADQUISICIÓN}

La doctrina de los comentaristas forales, viendo los antecedentes doctrinales de los analistas del derecho común distingufa a nivel teorico entre las posiciones del fundo dominante y sirviente, a pesar de no mencionarse en los fueros la terminología adoptada por los comentaristas forales. Entre otras posiciones distingura entre el dominum fundi servientis en oposicion al dominus fundi dominantis, recogiendo la terminologła de tradicion jurfdica romanistas.

También distingufan los referidos comentaristas forales a pesar de no mencionarse en los fueros, las "servidumbres personales" y las "reales", según recayeran sobre el dueño de la finca o sobre la propia heredad sirviente.

Además, se diferenciaba entre "servidumbres continuas" y "discontinuas", según pudieran o no perderse por su calda en desuso durante un tiempo.

Aparte, reconocía la doctrina foral valenciana la existencia de servidumbres forzosas y voluntarias, según que el dueño de la finca sirviente estuviera o no obligado a soportarlas en beneficio de la dominante.

En cuanto al contenido de los fueros en esta materia los mismos proscribran las "servidumbres personales" cuando se imponfan individualmente al propietario de un fundo en favor del dueño de otro campo o de la propia finca, especificando en este caso que:

"Negú no pot posar aytal servitut en altruy camp o loch, ço es que culla fruyta, o si vaie deportar, o hi vaie menjar, o en altruy era batre son blat per raó de servitut" ${ }^{n}$.

\footnotetext{
'Albert d'Alabanya, Nolae super foris regni Valentiae. Biblioteca Universitaria de Valencia (BUV). Manuscritos (Ms.), $n^{0}$ 208, fol. $134 \mathrm{r}$ : "qualibet enim domus presumitur libera, nisi probetur servitutem debere".

sGiner RABAÇA (hijo), Notae super foris, BUV, Ms. 208, fol. 135 v.-r.

'Furs e Ordinacions, Lib. III, Rub XVI, Fur V. Este fuero reproduce literalmente la Ley Fr. 8 p. De servitutibus, $8,1$.
} 
A pesar de ello, la doctrina admitfa la existencia de algunas servidumbres personales si se hablan adquirido por prescripcion. Asl, afirmaba Guillem Jaffer, que si se trataba de servidumbres discontinuas, debfase distinguir a su vez entre las personales y las reales, considerándose imprescriptibles las servidumbres reales discont'́nuas salvo prescripcion por uso desde tiempo inmemorial. Si fueran discontinuas personales, sólo prescribirían con o sin título por el transcurso de un plazo de desuso de larga duración, de 30 a 40 años?. denuncia .

En todo caso, la prescripción se interrupra mediante la simple

Respecto al modo de adquisición de las servidumbres voluntarias parece que precisaban el consentimiento expreso o tácito de los propietarios de fincas comunes de varios propietarios.

Respecto a las servidumbres continuas, opinaba Guillem Jaffer, que podfan obtenerse mediante pactos y estipulaciones entre las partes asf como mediante prescripción por el uso. Del mismo modo, se podfan adquirir las servidumbres continuas, usándolas por un perlodo de diez años entre dueños presentes de las fincas y por uso de veinte años entre ausentes. También se podian perder no haciendo uso de ellas durante el mismo período; empezando a correr esta prescripción desde el momento que se intento hacer uso del derecho por el fundo dominante y el dueño del sirviente prohibio ejercer el correspondiente derecho inherente a la servidumbre?.

Sin embargo, habla normas forales que preceptuaban la imprescriptibilidad de la servidumbre de uso sobre las eras ${ }^{10}$. En el mismo sentido se

\footnotetext{
'Guillem JAFreR, Notae super foris, BUV, Ms. 208, fol. 137 v-138 r: "...si servitus fuerit continua vel quasi verum est quod longuo tempore prescribuntur, scilicet, decem annis inter presentes at XX inter absentes...; sed si fuerit discontinua, ut est servitus personalis que debetur persone; et realis que debetur rey; si fuerit realis sto cum glossa quod non prescribitur nisi a tempore a quo non extat memoriae... Si fuerit personalis et etiam licet discontinua bene preacribitur longo tempore cum titulo, si autem sine titulo XXX vel XL annis".

"RABuça (hijo) Nolae super foris, BUV, Ms. 208. fol. 137 r, 138 v.: "Sola denunciatio internumpit preacriptionem".

'JAFFER, Notce super foris, BUV, Ms. 208, fol. 135 r-v.: "(servitus) possunt acquiri paccionibus a stipulationibus, a solo simplici usu $X$ annonum... Item, amittit servitus non utendo per $X$ annoo sicut notatur quod iatud decennium incipit currere ab eo tempore quo ego incepi hedifficare at tu prohivisti iure servitutis".

${ }^{10}$ Furs e Ondinacions, Lib. III, Rub. XVI, Fur VIII: "Si alcú en la tua era no ha dret per quand que temps aquell usard o emprard aquella era no nou a tu qui eat senyor d'aquella era".
} 
pronunciaba la doctrina del célebre comentarista foral y vicecanciller de la Real Audiencia de la Corte, micer Domènec Mascó a fines del siglo XIV"

\section{SERVIDUMBRes PREDIALES TIPIFICADAS EN fUEROS}

En cuanto a las servidumbres legales nísticas expresamente tipificadas en los fueros valencianos, eran los siguientes:

1. "Servitut de conservar les carreres publiques".

2. "Servitut de passar".

3. "Servitut de menar aygua a regar". vehr".

4. "Servitut de pendre o de poar aygua en lo pou o font de son

5. "Servitut d'albeurador".

6. "Servitut de l'arbre d'alcu que penjara sobre camp d'altre".

7. "Servitut d'era".

Aparte podian constituirse otras privadamente, ya que no se vedaba en fueros sino la constitución de servidumbres personales.

\section{1. "Servitut de conservar les carreres públiques"}

Los fueros valencianos, disponfan que los campos lindantes con las vías públicas antiguas por las que se accedía a las distintas heredades, estaban obligados por su propio interés a mantener las mismas abiertas sin estrecharlas ni empeorarlas ${ }^{12}$.

Además, venfan obligados a repararlas y conservarlas a su costa, junto con los demás vecinos que accedian a sus heredades a través de las mismas, si no querran verse forzados a dar paso de camino por sus propias heredades ${ }^{13}$.

\footnotetext{
"Domènec MAsco, Nolae super foris, BUV, Ms. 208; fol. 136 r: "...non currit servitus si per mille annos in area mea que est iuxta domum meam non edifficavi...".

${ }^{12}$ Furs e Ordinacions, Lib. I. Rub. II. Fur VII: "Les carreres antigues per les quals va hom a les heretats, als orts, $O$ a les vinyes, a les alqueries o a altres lochs quals que sien, no sien closes ne stretes ne pijorades".

${ }^{13}$ Furs e Ordinacions, Lib. III. Rub. XVI. Fur XIX: "Si carrera pública per scorrentiment - per forga d'aygua de flum o de pluia serd pijorada o de tot en tot serd destruïda: los vehins qui són pus prop d'aquella carrera la deuen refer e adobar, o donar carrera per lur terra propia". Este fuero, adaptaba la Ley fr. 14, apartsdo 1: Quemadmodum servitutes amittantur,
} 
Por la propia naturaleza de ser de dominio y uso público las tierras por las que discurrfan los caminos rurales, resultaba una servidumbre imprescriptible, según la regulación foral ${ }^{14}$.

\section{2. "Servitut de passar"}

A diferencia del derecho romano, los fueros valencianos, siguiendo una corriente medieval hispana, admitían no sólo la servidumbre de paso a través de fundos vecinos para el acceso a las propias heredades, constitufda de forma voluntaria entre el dueño del fundo sirviente y el del dominante, sino también la constituida de forma forzosa para el sirviente, a fin de que el dominante pudiera llegar a una vía pública ${ }^{\text {is }}$.

Para exigir la servidumbre forzosa de paso, no sólo debra constatarse el hecho de estar la finca dominante rodeada de otras posibles fincas sirvientes, sino que además se tenfa que comprobar que no tenfa o habla tenido un paso antiguo para acceder desde un camino "...ni sia sabut per qual loch cert antigament ell hagues carrera on pogués entrar a aquell camp seu...". Sólo en este caso, o en el de no conocerse tal paso, deberfa constituirse la servidumbre forzosa y gratuita sens tot preu de paso ineludiblemente a cargo del fundo que sufriera menos daño al darla al vecino que careciese de acceso a vía pública, al establecerse en fueros que los fundos sirvientes serian los de los vehins que menys dan hi haurdn... ${ }^{16}$.

La servidumbre de paso asf constituida forzosamente, se adquirfa en virtud de resolución judicial; aunque podfa también adquirirse voluntariamente por contrato covinença o prescripción (uso sin contradicción durante diez años); en cuyo caso, la servidumbre no se perdfa, sino por desuso durante otros diez años continuos ${ }^{17}$; con la salvedad de ampliarse el

$8,6$.

"Furs e Ondinacions, Lib. VII, Rub. I, Fur I.

is Arcadi GARCU I SANZ i Germa COLON, Furs de Valencia, Barcelona, Barcino, vol. III, pp. 234-235; eneroncan la servidumbre forzosa foral de paso con una corriente hispana medieval (Cfr. Fuero Viejo de Cartilla, Lib. 4, tit. S, Ley 5; Fuero de Navam, Lib. VI, tit. 5, Cap. 1; y Fueros de Aragón, Lib. 3, Cap. 3: De consortibus eiusdem rei).

"Furs e Ordinacions, Lib. III, Rub. XVI, Fur XV.

"Furs e Ordinacions. Id. Id. Fun XIV y XX. El supuesto previsto en fueros de prescripción de 10 eños, paroce ser el previsto por Guillem Jáfer en sus comentarios forales que coincide con la Ley C. 14, De servitutibus a squa, 3, 34. 
plazo de prescripción a veinte años, si el dueño de la finca sirviente estaba ausente del lugar, según opinión defendida por la doctrina foral ${ }^{12}$.

\section{3. "Servitut de menar aygua a regar"}

La servidumbre de acueducto, de raigambre plenamente romana, se regulaba prolijamente en fueros, estableciéndose la posibilidad de su constitucion, tanto voluntariamente entre las partes, como forzosamente por via judicial.

En caso de exigirse el derecho de acueducto forzosamente, ante la negativa de la finca sirviente a dar paso de agua, se habra de constatar que el fundo dominante estaba rodeado de otras fincas y sin acceso a conducción de aguas de riego que se conociera desde antiguo. En tal caso, se buscarra el lugar menos dañoso para la finca sirviente, para que se hiciese la conducción de agua, y quedase constitufda la servidumbre de acueducto gratuitamente ${ }^{19}$.

Tanto las "Costums de Tortosa" como las "Ordinacions d'En Santacilia", seguran parece ser, a los fueros valencianos en este punto, reflejando la solución jurídica general prevista en el derecho musulmán sobre las aguas, la cual preceptuaba la constitución de servidumbres forzosas para el aprovechamiento de las aguas de ríos, pozos y fuentes ${ }^{20}$.

La aplicación del derecho musulmán en materia de acequias, acueductos y fuentes, se preceptuaba como regulación aprobada en los fueros valencianos, al decir:

10JAFFER, Notae super foris, BUV, Ms. 208. fol. 137 v-138 r.

${ }^{19}$ Furs e Ordinacions, Lib. III. Rub. XVI. Fur XV. A pesar de considerar Juan BENEYTO PEREZ (Instituciones de Derecho histórico espatiol, I, Barcelona, 1930, pp. 261-262); y Arcadi GARCIA SANZ i Germi COLÓN (Furs de Valencia, III, p. 235) que la regulación valenciana del derecho a la servidumbre forzosa de acueducto era peculiar de los Furs, encontramos regulaciones semejantes en las Costums de Tortosa, Lib. III, Cast. XIV, par. $4^{0}$; y también en Ins Ordinacions d'En Sanctacilia, publicadas por Jaime I, según Brocd (Cfr. Guillermo M". de BROCA, Historia del Derecho de Catalusia, Barcelona, 1918, pp. 307-308).

${ }^{20}$ ABOU YousOF YA'KOUB Livre de l'Impót foncier (Kicab el-Kharadj). Traducción E. Fagnan, Parí, Librairie Orientaliste, 1921, pp. 145-155. Cfr. también David SANTIU ANA, Instituzioni di Diritto musulmano malichila, Roma, 1926-43, Pp. 322-369; y Josk LÓPEZ ORTIZ, Derecho musulmán, Barcelona, 1932, pp. 188-189. 
...Enaxi que puscats d'aquelles regar e pendre aygues sens alcuna servitut e servici e tribut: e que prenats squelles aygues, scgons que antigarnent de c fo stablit e ecostumat en tempe de samahins"

El derecho de todo propietario de tierra a tomar las aguas que pudiese necesitar para riego de sus heredades, según la cabida de su fundo, también se preceptuaba expresamente en los fueros valencianos:

\footnotetext{
...si alcun poseccix alcuns lochs que no han acostumat tro aci de regar, pusque pendre l'aygua ab que rech aquells lochs, segons la manera del loch o de la posecasio: e que rech equells lochs sens vet alcú...
}

Como consecuencia de la existencia de la servidumbre de acueducto, se preceptuaba la vigencia de una serie de servidumbres accesorias para los regantes y vecinos, que deblan hacerse cumplir por los acequieros:

1. "Facen una vegada en l'any de sol a sol escombrar los braçals".

2. "Facen tots los partidors de les aygues".

3. "Refacen els ponts per los quals negú no passa sino els hereters".

4. "Refacen les cèquies que seran rotes, segons la manera e la forma e'l stat antich".

5. "E si la reclosa serd tota trencada reparen aquella enfre $\mathrm{X}$ dies en hivern e enfre VIII dies en stiu, segons la forma e'l stat e la manera antiga"22.

Aparte de la obligación de todo regante de limpiar las acequias y brazales generales, tenía el deber de mondar su propia regadera; y el de dar paso junto a la misma hasta el rlo o acequia principal a fin de que el dueño del fundo dominante de la servidumbre de acueducto, pudiera acceder al río y a la referida acequia, para limpiarla depositando los lodos y escombros de las reparaciones en este espacio situado junto a la conducción. Decfan asf los fueros:

Si alcu per lo camp de son vehi hauría dret: ço es servitut de menar aygua a regar lo eeu camp, perge deu haver carrera al riu o a la cequia, a ecombrar o a refer: e'l senyor del camp deu a ell lexar spay de cascuna part de la cequia en que pusque posar aquelles coses que serán ops a refer lo riu

\footnotetext{
${ }^{21}$ Furs e Ordinacions, Lib. III, Rub. XVI, Fur XVI.

${ }^{2}$ Furs e Ordinacions, Lib. IX, Rub. XXOX, Fun IV y V.
} 
o cequis: e en que pusque posar les scombradures e el terquim d'aquell riu o d'aquella cequia's.

La vigencia de un derecho a constituír servidumbres forzosas de acueducto era una consecuencia inmediata del fuero que otorgaba a los poseedores de tierras regables, el derecho a aprovechar libremente las aguas de los ríos, acequias y fuentes del reino; asi como las aguas sobrantes de los manantiales privados ${ }^{24}$.

Tanto si se constitura la servidumbre de acueducto de manera forzosa, como si nacía de forma voluntaria, por convenio entre las partes; el dueño del fundo sirviente tenfa derecho a señalar el punto concreto por donde debra pasar la conducción. Pero si no lo hacia, entonces podía designarlo el dueño del fundo dominante, por el lugar menos dañoso para la finca sirviente.

En este sentido, el consentimiento ininterrumpido del paso de agua por un fundo por un perfodo de diez años, sin contradicción del dueño del fundo sirviente, suponfa suficiente plazo de prescripción adquisitiva de la servidumbre de acueducto ${ }^{25}$.

A "sensu contrario", no siempre se producfa la prescripción extintiva de la servidumbre por desuso durante diez años, pues en el caso de que la falta de utilización del agua de riego durante un plazo superior al mencionado, se debiera a disecación; entonces podía recobrarse la servidumbre, si renacía la fuente, pasados los diez años. Así, se decía en fueros:

En aqueat cas aquell vehi no pert lo dret que havie de menar la aygua al seu camp a regar; ni pert la servitut que aqui havie: car no usa per aquell temps damunt dit, ço es $X$ anys... ${ }^{26}$

Este serfa uno de los típicos casos en que se apreciaría una servidumbre discontinua real, como las estimadas por el comentarista foral

\footnotetext{
${ }^{23}$ Furs e Ordinacions, lib. III, rub. XVI, fur XVII. Este fuero tomaba la regulación de la Ley fr. 11. "Communia prediorum tam rust., quam urb. 8, 4. Su regulación debe comparare con la de las Ordinacions d'En Sanctactia, cuyo capítulo 9 decía: "De recs de aygua. Encare que si ningun hom haurd de dar passatge d'aygua per menar a algunas honors, que haja a lexar opay, o carrera de dos parns e mig de destre, ultra lo rec hon la dita aygua passara, qui sia aprés" (Cfr. Constitucions $i$ altres Drets de Cathalunya. Prandtiques, lib. IV, tit. II, n. 1).

${ }^{24}$ Furs e Ordinacions, Lib. III, Rub. XVI, Furs II, XVI y XXXVII.

${ }^{25}$ Furs e Ordinacions, Lib. III, Rub. XVI, Fur XX.

${ }^{26}$ Furs e Ordinacions, Lib. III, Rub. XVI, Fur XXXII.
} 
medieval micer Guillem Jaffer; el cual defendía que este tipo de servidumbres necesitaban para su prescripción de una larga duración (prescripción inmemorial) ${ }^{27}$.

3.4. "Servitut de pendre o de poar aygua en lo pou o font de son veht"

Esta servidumbre consistía en el derecho que se otorgaba al dueño de una finca para sacar agua de un pozo o fuente de campo ajeno, con el fin de utilizarla en su heredad.

Generalmente, este tipo de servidumbre, se concertarfa voluntariamente entre las partes, e inclura accesoriamente el derecho a pasar por la finca sirviente a fin de poder tomar el agua.

Si se habla obtenido esta servidumbre por prescripción de uso del agua de la finca vecina, se entendra igualmente adquirida la servidumbre accesoria de paso, si el dueño del fundo sirviente no hubiere hecho contradicción del mismo por diez años.

Obtenida esta servidumbre, el derecho a tomar las aguas del fundo vecino, se consideraba de naturaleza discontínua; por lo cual no prescribfa por desuso durante diez años, sino que a pesar de que el pozo o la fuente se secase temporalmente, se restablecía cuando volviese a dar agua; según el mismo régimen estimado en la servidumbre de acueducto ${ }^{23}$.

Esta regulación coincidía con los preceptos referentes a las servidumbres de aprovechamiento de aguas del derecho musulmán, del cual parece que se tomaron por los fueros valencianos, según los mismos declaraban expresamente ${ }^{29}$.

Aparte de la existencia de una servidumbre positiva de aprovechamiento de las aguas del fundo vecino, los dueños del fundo dominante y sirviente podran pactar una "servidumbre negativa" para este último, que le obligara a abstenerse de buscar y explotar un nacimiento de agua sito en su finca, en provecho de la finca dominante, a fin de que ésta contara con el

\footnotetext{
${ }^{27}$ JAPFER, Notae super foris, BUV, Ms. 208, fol. 137 r. 138 r. Este autor defendia que la preacripción inmemorial para la extinción de eate tipo de eervidumbres discontinuas reales era In defendida por los glosadores (a tempore a quo non extal memoria).

${ }^{20}$ Furs e Ordinacions, Lib. III, Rub. XVI, Furs XVIII, XX, XXXII.

${ }^{29}$ Furs e Ordinacions, Lib. III, Rub. XVI, Fur XVI. Cfr cambién ABOU YousOF YA'KOUB, Livre de l'impos foncier, pp. 148-149.
} 
agua necesaria para su explotación, la cual nacia en la propia heredad dominante. Todo, para evitar que con la utilización del nacimiento de la finca sirviente, se mermara el caudal o se secara el de la finca dominante ${ }^{30}$.

\section{5. "Servitut d'albeurador"}

Esta servidumbre consistfa en el deber de ofrecimiento de agua libremente a todo vecino poseedor de animales en los términos del lugar; con cuya servidumbre obtenfan el derecho a beber ellos y a llevar a abrevar sus bestias de labor y ganados cuando quisieran.

Obligaban los fueros a todo señor territorial a mantener en sus respectivos señorfos dos abrevaderos públicos, respectivamente situados, uno en la parte alta de la población; y otro, en la parte baja ${ }^{31}$.

En ocasiones, la constitución de este tipo de servidumbres de abrevadero, nacía del interés en facilitar a los ganados el apacentamiento en un término, con el fin de percibir los correspondientes derechos de herbajes, asadura, diezmos de las crías y otros semejantes que exigfan los señores a los ganaderos.

Con esta justificación encontramos un convenio firmado en 1307 entre los señores de Picassent y Monserrat, que enfranquecía el uso de los abrevaderos de estos términos, a fín de que los pastos de los mismos fueran preferidos por los numerosos ganaderos de diversas zonas valencianas y aragonesas que frecuentaban estos extensos términos, ricos tradicionalmente en zonas de pasto. Este tipo de disposiciones se consignaban a menudo en las cartas de población, fueran de concesión real como la de Xátiva (1250) o señorial, como la del castillo de Arenós (1271) y Sollana (1277).

En no pocas ocasiones, la constitución de servidumbres de abrevadero provenía de enfranquecimientos obtenidos por los lugares de manos de la Corona $^{32}$.

${ }^{30}$ Furs e Ordinacions, Lib. III, Rub. XVI, Fur. XII in fine.

${ }^{31}$ Furs e Ordinacions, Lib. I. Rub. II. Fur I.

${ }^{3}$ Archivo del Reino de Valencia (ARV). Justicia Civil. Manaments i Empares. Any 1635. Lib. 5, ma. 41, fol. 43 r., 46 v. Cfr. también Enric GUINOT, Cartes de poblament medievals valencianes, Valencia, 1991, doc. 83 (1250, agosto, 18); doc. 146 (1271, abril, 6); doc. 176 (1277, abril, 10). 


\section{6. "Servitut de l'arbre d'alcú que penjard sobre camp d'altre"}

Al considerarse en los fueros valencianos los márgenes de las heredades de dominio común entre los dueños de los fundos colindantes, se decía que su alteración no podía hacerse unilateralmente por ninguna de las partes sin incurrir en una cuantiosa multa y en la pérdida de la tierra que se hubiese obtenido al modificarse los linderos.

En otro sentido se preceptuaba en la regulación foral la propiedad de los ribazos lindantes con los ríos, la cual se consideraba agregada a los campos vecinos, asf como la titularidad de los árboles que existiesen plantados en los referidos ribazos.

Respecto al árbol que estando plantado en un fundo, recala sobre el fundo vecino, los fueros preceptuaban la constitución de una servidumbre en favor del dueño del fundo sobre el que estaba la rafz del árbol, obligando al dueño del fundo sobre el que caran las ramas a soportarlas si no hacian daño a su propia finca, que a efectos de la servidumbre se consideraba "fundo sirviente" ${ }^{33}$.

\section{7. "Servitut d'era"}

Consideraban los fueros como servidumbre legal también, la constituida sobre las eras en favor de los dueños de las heredades que tuviesen derecho a realizar en ellas las diversas labores agricolas de uso más común: trilla, secado, batida y otras semejantes. Disponfan los fueros también que este tipo de servidumbres no podfan prescribirse por uso consentido del dueño de la era, no pudiendo tampoco establecerse por uno de los propietarios comuneros de la misma, sin el consentimiento de

\footnotetext{
${ }^{33}$ Furs e Ordinacions, Lib. I, Rub. I, Furs III y IV; Ibidem, Lib. III, Rub. XVI, Fur XXVI; Ibldem, Lib. IX, Rub. XII, Fur XI. Este fuero se inspiraba en la Ley fr. 1 párafo 9; "De artoribus ceodendis". Semejante a la regulación valenciara es la que se encuentra en las Costums de Tortosa (Lib. III, coat. XXII, Parr. 1), aunque conteniendo una nomativa má extensa.
} 
todos $^{34}$. Necesitaban por tanto para contituirse un título público de constitución de la servidumbre.

Aparte de las servidumbres forales rísticas podrian rastrearse otras urbanas más o menos relacionadas con la agricultura, tales como la de clavergueres e de stremeres $e$ de albellons, que haclan referencia al derecho de desagüe de unas fincas por otras; Tambien a las de "medianeria", "luces" y otras con menos relación agraria.

\section{DEFENSA Y REIVINDICACIÓN DE LAS SERVIDUMBRES}

En cuanto a las acciones que cada una de las partes de las servidumbres tenfa reconocidas para su defensa y reivindicación, Guillem Jáffer, afirmaba que correspondian a estas partes: actionem in rem, en sus variantes de la actionem in rem confessoriam para el dueño del fundo dominante contra el fundo sirviente; y la actionem in rem negatoriam, para el dueño del fundo sirviente contra el del dominante .

La acción confesorfa competía al dueño de la finca dominante que requiere del dueño de la sirviente que reconozca formalmente ante el juez que su finca tiene constituida una sevidumbre en favor de otra.

La acción negatoria competía interponerla al dueño de una finca que rechazaba el tener constituida una servidumbre en favor de otra que cuyo dueño estaba ejerciéndola ilegítimamente o pretendra ejercerla en el futuro ${ }^{35}$.

\footnotetext{
${ }^{34}$ Furs e Ordinacions, Lib. III, Rub. XVI, Furs VII y VIII. El primero de estos fueros establecía que el que usabe de una servidumbre sobre una era, no llegaba nunca a adquirirla por prescripción. Además, el segundo fuero referente al tema decía: "Si dos companons hau ran una era o un pati ensemps cominalment e un altre qui serd vehí d'aquella era o d'aquell pati lo qual havie servitut en aquella era o en aquell pati; go es que negú no y pogues edificar ni obrar, e aquell vehí atorgara a un d'aquells companyons que pogués en aquella era o en aquell pati odificar, l'altre companyó vedan a aquell a qui és atorgat que y edificds no y pot edificar ni obrar".

${ }^{35}$ JAFFER, Notae super foris, BUV, Ms. 208, fol. 135 v-r. Decía este autor: "Sed quas actiones habet contra vicinum suum pro servitutis rustica vel urbana.- Et respondeo, quod habet accionem in rem, scilicet confessoriam et negatoriam; confessoriam competit domino fundi qui aserit servitutem debere fundum vicini fundo suo; negatoriam competit domino qui negat fundum suum debere servitutem fundo vicini..."
} 


\section{RÉSUMÉ}

Les Furs de Valence furent le droit en vigueur a l'ancien règne de Valencie pendant l'Epoque apellee "foral" (1238-1707).

De toute cete legislation apellé "foral", nous etudions ici dans nôtre article les servitudes agricoles comme une institution du droit agrarien qui réglait les relations entre fonds limitrophes a fin d'aider la protaction de l'agriculture.

La múthodologie employée dans nôtre étude consiste en l'analyse de la législation des Furs de Valence sur la matière des servitudes agricoles, tout completant cettes informations légals avec la documentation des archives, et la doctrine "classique" des commentateurs du droit romain (Baldo, Bartolo...) et commentateurs des Furs de Valencia (Alabanya, Guillem Jáffer, Rabaces, Johan, Mascó, Bonifaci Ferrer, Belluga...).

\section{SUMMARY}

The survey intends to analize the institutions developed in the XIII and XIV centuriea for the exploitation of the land, considering the social and economical circumstances that had an influence on these institutions since the publication of the "Furs de Valencia".

Thus, this survey is focused on the legal-historic agricultural servitude in the Kingdom of Valencia.

This analysis about the ways of agricultural servitude is complemented with an historical introduction on servitude law.

The methodology employed consists in an analysis of the legal institutions according the legislation, the documentation of archives and legal matters (Commentators of Roman Law, such as Bartulo, Baldo...); and commentators of Valencian Law (Alabanya, Jaffer, Rabaçes, Johan, Mascó, Bonifaci Ferrer, Belluga...). 